\title{
Drought-stress Effects on Physiology, Growth and Biomass Production of Rainfed and Irrigated Bell Pepper Plants in the Mediterranean Region
}

\author{
Sebastiano Delfine ${ }^{1}$ \\ Dipartimento di Scienze Animali Vegetali e dell'Ambiente, Università degli Studi del Molise, via De \\ Sanctis, 86100 Campobasso, Italy \\ Francesco Loreto \\ Consiglio Nazionale delle Ricerche -Istituto di Biochimica ed Ecofisiologia Vegetale, 00016 Monterotondo \\ Scalo (Roma), Italy \\ Arturo Alvino \\ Dipartimento di Scienze Animali Vegetali e dell'Ambiente, Università degli Studi del Molise, via De \\ Sanctis, 86100 Campobasso, Italy
}

\begin{abstract}
Additional INDEX words. Capsicum annuum, fluorescence, gas exchange, photosynthesis, $\mathrm{CO}_{2}$ transfer conductance, vegetative and fruit biomass, drought stress

Abstract. Physiological characteristics, growth, and biomass production of rainfed and irrigated bell pepper [Capsicum annuum L. var. anuum (Grossum Group) 'Quadrato d'Asti'] plants were measured in the semiarid conditions of a Mediterranean summer to determine if drought stress effects are transient and do not affect plant growth and crop yield or are persistent and adversely affect plant growth and crop yield. A low midday leaf water potential indicated the occurrence of transient drought stress episodes in rainfed plants during the first 2 months of the study. Later on, predawn water potential also increased, indicating a persistent drought stress condition despite the occurrence of some rainfall. Photosynthesis was reduced when stress conditions developed, but the reduction was transient and limited to the central part of the day during the first 2 months. As plants aged, however, the impact of drought stress on photosynthesis was not relieved during the overnight recovery period. Stomatal conductance was reduced both during transient and permanent stress conditions while $\mathrm{CO}_{2}$ transfer conductance (i.e., conductance to $\mathrm{CO}_{2}$ inside the leaf) was only reduced when photosynthesis inhibition was unrecoverable. However, chloroplast $\mathrm{CO}_{2}$ concentration was higher in rainfed than in irrigated leaves indicating that $\mathrm{CO}_{2}$ availability was not limiting photosynthesis. Nonphotochemical quenching of fluorescence increased significantly in rainfed leaves exposed to permanent stress indicating the likely impairment of ATP synthesis. Transient inhibition of photosynthesis did not significantly affect leaf area index and biomass production, but growth was significantly reduced when photosynthesis was permanently inhibited. Fruit dry weight was even higher in rainfed plants compared to irrigated plants until drought stress and photosynthesis reduction became permanent. It is suggested that bell pepper growth without supplemental irrigation over the first part of the vegetative cycle does not impair plant growth and may even be useful to improve yield of early fruit.
\end{abstract}

Severe drought stress may impair many plant functions but the main effect is reduction of carbon fixation. This, in turn, may differentially affect plant growth and production depending on many variables such as the length of the stress, the vegetative status of the crop, and the occurrence of other environmental stress (e.g., high light irradiance and high temperatures). One of the most well known responses to drought stress is stomatal closure and the subsequent increase of resistance to $\mathrm{CO}_{2}$ diffusion in leaves (Kaiser, 1987). The concentration of $\mathrm{CO}_{2}$ at the site of its fixation (the chloroplast) may be further restricted by resistances inside the leaf mesophyll (Loreto et al., 1992). These resistances are also likely to increase in water-stressed leaves (Cornic and Massacci, 1996; Loreto et al., 1997).

The view that resistances to $\mathrm{CO}_{2}$ diffusion are the only factor responsible for the reduction of carbon fixation in water-stressed leaves has often been challenged. Many studies have demonstrated that biochemical and photochemical reactions of $\mathrm{CO}_{2}$

Received for publication 23 June 2000. Accepted for publication 13 Dec. 2000. We thank Sig. Giuseppe Santarelli for measuring micrometeorological data and Sig. Luigi Santini for field farming. The cost of publishing this paper was defrayed in part by the payment of page charges. Under postal regulations, this paper therefore must be hereby marked advertisement solely to indicate this fact. ${ }^{1}$ Corresponding author; e-mail: delfine@unimol.it. assimilation may also be directly impaired by drought stress and, therefore, photosynthesis is not simply down-regulated in response to low internal $\mathrm{CO}_{2}$ (Gimenez et al., 1992; Hanson and Hitz, 1982). A recent report by Tezara et al., (1999) provided evidence that Rubisco characteristics and some photosynthesis intermediates are unaffected by mild drought stress, but ATP synthesis is sensitive to drought stress and may strongly reduce ribulose 1,5-bisphosphate (RuBP) content in water-stressed leaves. However, Tezara et al. (1999) also cautioned that this may not occur under field conditions when the stress develops slowly and plants may respond to drought by adjusting metabolism and resistances to water loss through stomata (Faver et al., 1996; Mojayad and Planchon, 1994; Ortiz-Lopez et al., 1991; Quick et al., 1992).

Summer crops of the Mediterranean region generally experience recurrent drought stress episodes during their vegetative and reproductive cycles. Irrigation water is a limited resource and water-saving practices are highly encouraged. It is therefore important to determine whether drought stress causes physiological consequences in field-grown plants that are a) transient and unable to affect plant growth and crop yield, or b) persistent and limiting plant growth and crop yield.

Bell pepper [Capsicum annиum var. aпиит (Grossum group)] 
is among the most susceptible horticultural plants to drought stress because of a wide transpiring leaf surface and high stomatal conductance (Alvino et al., 1994). An adequate water supply is required during the total growing period to obtain high yield (Doorenbos and Kassam, 1986). Under soil-water stress, pepper plants reduce leaf water potential, LAI (leaf area index) and the amount of light intercepted by the canopy (Alvino et al., 1994). Drought stress, also has been shown to affect harvested pepper fruit yield (Lurie et al., 1986), and senescence of leaves of corn (Zea mays L.) (Alvino et al., 1999) and pepper plants (Yanez et al., 1992).

In the present investigation we studied physiological and metabolic processes affected by drought stress in field-grown bell pepper and quantified the effects of drought stress on physiology, growth, and productivity of pepper in environmental conditions typical of the Mediterranean region. The objectives of this study were to establish if and when water supplements are useful or necessary to support various physiological processes and avoid yield reduction of pepper and to provide guidelines for a more efficient and sustainable use of irrigation water.

\section{Materials and Methods}

Plants material, experimental design, drought Stress MEASUREMENTS, AND GROWTH ANALYSIS. Plants of 'Quadrato d' Asti' bell pepper were transplanted on loamy soil at the six-leaf stage, in rows $0.8 \mathrm{~m}$ apart to obtain a crop density of 5 plants $/ \mathrm{m}^{2}$. During the season, plants were regularly fertilized and weeds were controlled by hand tillage.

Eight plots, each $30 \mathrm{~m}^{2}$, were formed at the beginning of June 1998 in an experimental field of Consiglio Nazionale delle Ricerche-Istituto di Biochimica ed Ecofisiologia Vegetale (Roma, Italy, $42^{\circ}$ latitude) close to an agrometeorological field station. Plots were arranged in a randomized complete block design. Potential evapotranspiration was calculated from micrometeorological data using the Penman-Monteith formula (Doorenbos and Kassam, 1986). The values were corrected with crop coefficients depending on the crop development stage ( 0.4 for the initial period, 0.7 for crop development period, 1 for midseason, 0.9 for late season, and 0.85 at harvest) as suggested by Doorenbos and Kassam (1986) to provide crop evapotranspiration (ETcrop). In the control plots, ETcrop was fully restored by drip irrigation. After plant establishment, irrigation was withheld in four plots [0 days after treatment (DAT)].

Midday and the predawn leaf water potentials were used as stress indices. They were measured on 16 fully expanded leaves of different plants with a pressure chamber (model 3005; Soilmoisture Equipment Corp, Santa Barbara, Calif.).

Growth was determined for seven replicates during the crop cycle. Fruit, leaves, and stems were oven dried at $75^{\circ} \mathrm{C}$ for $48 \mathrm{~h}$ and dry weights (DWs) were recorded. Prior to drying leaf area was measured with a leaf area meter (LI-3100; LI-COR, Inc., Lincoln, Nebr).

MEASUREMENTS OF PHOTOSYNTHETIC PARAMETERS. Net photosynthesis $\left(\mathrm{P}_{\mathrm{n}}\right)$ and stomatal conductance $\left(\mathrm{g}_{\mathrm{s}}\right)$ were measured on fully expanded leaves during the crop cycle in the field with a portable gas exchange system (LI-6400) and a system described by Loreto et al. (1992), except that an infrared gas analyzer (LI6262) and a small leaf cuvette enclosing a leaf area of $4.9 \mathrm{~cm}^{2}$ were used. The leaf was irradiated by an optic fiber ring connected to a light source (KL1500; Schott, Mainz, Germany). Measurements were recorded on seven fully expanded leaves selected randomly on different plants. Simultaneous gas exchange and fluorescence measurements were made using a variable irradiance when measuring the light response of photosynthesis, and at a saturating irradiance $\left(1800 \mu \mathrm{mol} \cdot \mathrm{m}^{-2} \cdot \mathrm{s}^{-1}\right)$ for other measurements. In all cases the leaf temperature was maintained at $25^{\circ} \mathrm{C}$ by circulating thermostatically regulated water in the body of the cuvette. Photosynthetic $\mathrm{O}_{2}$ sensitivity was calculated from the relation: $\left(P_{n} 2-P_{n} 20\right) / P_{n} 2$, where assimilation $P_{n} 2$ and $P_{n} 20$ are photosynthesis at low $(2 \mathrm{kPa})$ and ambient $(20 \mathrm{kPa}) \mathrm{O}_{2}$ pressure.

Fluorescence was monitored as described by Loreto et al. (1992), except that the terminal end of the optic fiber used for fluorescence measurements and for saturating light pulses $(10,000$ $\mu \mathrm{mol} \cdot \mathrm{m}^{-2} \cdot \mathrm{s}^{-1}$ ) was inserted inside the fiber ring normal to the leaf plane. This allowed the fluorescence fiber to reach the cuvette without shading the leaf.

The ratio between variable and maximal fluorescence $\left(\mathrm{F}_{\mathrm{v}} / \mathrm{F}_{\mathrm{m}}\right)$ was measured on dark-adapted leaves for $30 \mathrm{~min}$ to estimate the effect of drought stress on photochemical efficiency. The fluorescence emission in response to actinic and saturating light was measured to estimate the rate of electron transport $\left(\mathrm{J}_{\mathrm{f}}\right)$ according to the following equation: $\mathrm{J}_{\mathrm{f}}=\mathrm{DF} / \mathrm{Fm} \times \mathrm{a} \times 0.5 \times$ photosynthetically active radiation $(P A R)$, where $\mathrm{DF} / \mathrm{Fm}$ is quantum yield of electron flow to photosystem II (Genty et al., 1989). The overall leaf absorptance (a) was measured with an integrating sphere (LI$1800-12 \mathrm{~S}$ ) throughout the experiment. The factor 0.5 was chosen assuming that light is distributed equally between the two photosystems (Loreto et al. 1992). PAR is the incident irradiance.

Nonphotochemical quenching of fluorescence (qNP) was estimated according to van Kooten and Snel (1990) from maximal and minimal fluorescence in the dark $\left(\mathrm{F}_{\mathrm{m}}\right.$ and $\left.\mathrm{F}_{\mathrm{o}}\right)$ and at an irradiance of $800 \mu \mathrm{mol} \cdot \mathrm{m}^{-2} \cdot \mathrm{s}^{-1}\left(\mathrm{~F}_{\mathrm{m}}{ }_{\mathrm{m}}\right.$ and $\left.\mathrm{F}^{\prime}{ }_{\mathrm{o}}\right)$ : $\mathrm{qNP}=1-\left(\mathrm{F}_{\mathrm{m}}{ }_{\mathrm{m}}-\mathrm{F}^{\prime}{ }_{\mathrm{o}}\right) /$ $\left(\mathrm{F}_{\mathrm{m}}-\mathrm{F}_{\mathrm{o}}\right)$.

Transfer conductance $\left(\mathrm{g}_{\mathrm{w}}\right)$ of $\mathrm{CO}_{2}$ was determined as described by Loreto et al. (1994). Briefly, the electron transport rate calculated by gas exchange $\left(\mathrm{J}_{\mathrm{c}}\right)$ and measured by fluorescence $\left(\mathrm{J}_{\mathrm{f}}\right)$ are compared at an irradiance of $800 \mu \mathrm{mol} \cdot \mathrm{m}^{-2} \cdot \mathrm{s}^{-1}$. Measurements at higher irradiance would be imprecise because of the low fluorescence yield (Loreto et al., 1994). If $\mathrm{J}_{\mathrm{f}}=\mathrm{J}_{\mathrm{c}}$ under nonphotorespiratory conditions $\left(2 \mathrm{kPa} \mathrm{O}_{2}\right)$ but $\mathrm{J}_{\mathrm{f}}>\mathrm{J}_{\mathrm{c}}$ under photorespiratory (ambient air) conditions, it is assumed that $\mathrm{c}_{\mathrm{i}}$ [the intercellular $\mathrm{CO}_{2}$ partial pressure used to calculate $\mathrm{J}_{\mathrm{c}}$ according to von Caemmerer and Farquhar, (1981)] is higher than $\mathrm{c}_{\mathrm{c}}$ (the $\mathrm{CO}_{2}$ partial pressure in the chloroplasts). The internal resistance which causes the decrease from $c_{i}$ to $c_{c}$ can be calculated by assuming that $\mathrm{J}_{\mathrm{f}}$ is the actual electron transport rate. Substituting $J_{c}$ with $J_{f}: g_{w}=P_{n} /\left[\left(c_{i}-\Gamma^{*} \times\left(J_{f}+8 \times\left(A+R_{d}\right)\right] / J_{f}-4 \times\left(A+R_{d}\right)\right.\right.$, where $P_{n}$ is the photosynthetic rate, $R_{d}$ is dark respiration as measured from gas exchange on the dark adapted leaf, and $\Gamma^{*}$ is the $\mathrm{CO}_{2}$ compensation point that would occur in the absence of $\mathrm{R}_{\mathrm{d}}$, calculated according to Brooks and Farquhar (1985).

The fluorescence gas exchange method has been tested under a wide range of conditions and on many plant species. Detailed descriptions of the method, its sources of error, and comparisons with measurements of $\mathrm{g}_{\mathrm{w}}$ determined by on-line fractionation of stable carbon isotopes can be found in previous reports (Harley et al., 1992; Loreto et al., 1994). Transfer conductance measurements of $\mathrm{CO}_{2}$ were repeated on seven different leaves of different plants.

Rubisco ANALYSIS. Leaf samples $\left(3.8 \mathrm{~cm}^{2}\right)$ were frozen in liquid nitrogen immediately after gas-exchange measurements to measure Rubisco activity and content. Briefly, frozen leaves were ground in a chilled mortar with $30 \mathrm{mg}$ polyvinylpolypyrrolidone 
(PVPP), quartz sand, and $2 \mathrm{~mL}$ of extraction buffer $(100 \mathrm{~mm}$ bicine $\mathrm{pH} 8,10 \mathrm{~mm} \mathrm{MgCl}_{2}, 5 \mathrm{~mm}$ dithiothreitol (DTT), $1 \mathrm{~mm}$ ethylendiamminetetracetic acid (EDTA), and $0.02 \%$ (w/v) bovine serum albumin (BSA). The solution was centrifuged at $10,000 g_{\mathrm{n}}$ for $10 \mathrm{~s}$. A fraction of the supernatant was used to determine total carboxylase activity of Rubisco by a spectrophotometric method (Sharkey et al., 1991). Another fraction of the supernatant was added to a denaturing solution [20\% sodium dodecyl sulfate (SDS), $20 \% \beta$-mercaptoethanol, and $200 \mathrm{~mm}$ Tris $\mathrm{HCl} \mathrm{pH} \mathrm{6.8]} \mathrm{at} 95^{\circ} \mathrm{C}$ for $5 \mathrm{~min}$. Rubisco content was determined on the denatured solution by SDS-PAGE (Delfine et al., 1998), using $14 \%$ acrylamide gel. Gels were stained with Coomassie brilliant blue R-250, destained, and scanned at $550 \mathrm{~nm}$ using a dual-wavelength flying spot scanner (CS-9000, Shimadzu, Tokyo, Japan). Measurements were repeated on seven different leaves of different plants.

Statistical Analysis. The environmental parameters (temperatures, rainfall and ETcrop) are reported as single reading. Temperatures were measured every $1 \mathrm{~min}$, and the data collected are averaged every $30 \mathrm{~min}$ on the data loggers. Rainfall and ETcrop were measured daily. Photosynthesis, stomatal conductance, water potential and LAI are reported in figures as averages + standard errors $(n=7$ for photosynthesis and LAI data, $n=16$ for water potential data). The biochemical and physiological data of Table 1 , in addition, are separated statistically by $t$ test $(\mathrm{n}=7$, $P<0.05)$. Statistical separation by $t$ test $(\mathrm{n}=7, P<0.05)$ was also performed on the growth data shown in Fig. 8.

\section{Results}

Plants were cultivated in environmental conditions typical of summer in central Italy. Days were cloudless over most of the experimental period. The maximum temperature was generally $>30^{\circ} \mathrm{C}$ for 2 months after starting the treatment and the minimum temperature was always $>10^{\circ} \mathrm{C}$ (Fig. 1). The seasonal evapotranspiration demand (Fig. 2) was not met by precipitation which was scant particularly during the first month of the experiment (Fig. 1).

Photosynthesis and stomatal conductance under saturating irradiance $\left(1800 \mu \mathrm{mol} \cdot \mathrm{m}^{-2} \cdot \mathrm{s}^{-1}\right)$ and optimal leaf temperature $(25$

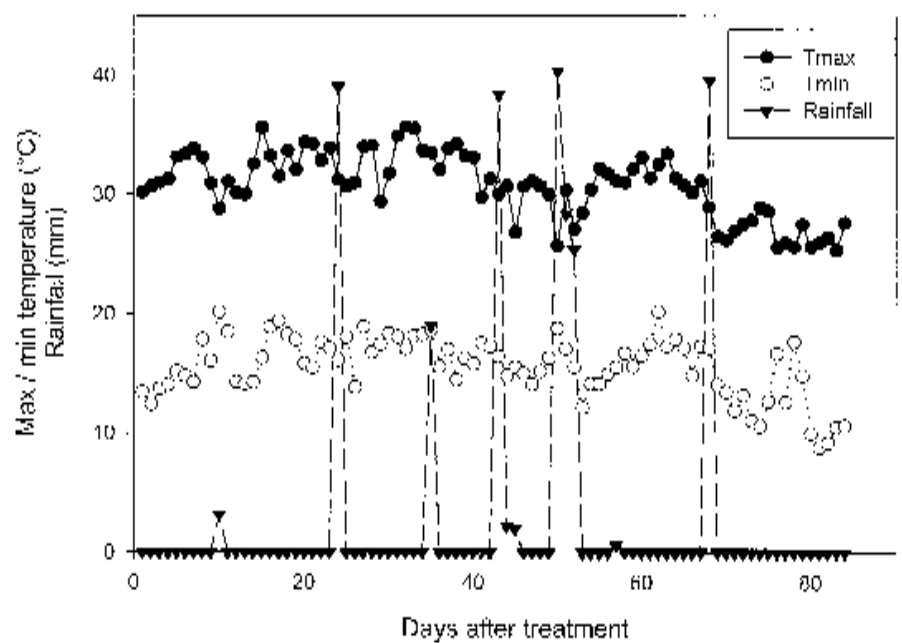

Fig. 1. Maximum (Tmax), and minimum (Tmin) daily temperatures and daily rainfall as recorded by the meteorological station during the experimental period (days after treatment, starting from the date on which rainfed and irrigated plants were treated differently). $\left.{ }^{\circ} \mathrm{C}\right)$ were similar for the first 2 months in irrigated and rainfed plants (Fig. 3). Transient and significant reductions of these parameters were observed in rainfed leaves 22 to 23 DAT and 42 DAT, just before two rainfalls (Fig. 1). After $\approx 2$ months, $P_{n}$ and $\mathrm{g}_{\mathrm{s}}$ of rainfed plants became significantly lower than in irrigated plants and this difference was observed until the end of the experiment (Fig. 3).

Three sets of field measurements representative of conditions when $P_{n}$ and $g_{s}$ were not affected (14 DAT), transiently affected (42 DAT) or permanently affected (66 DAT) by drought stress are presented in Figs. 4 to 6. Predawn and noon water potentials were not different in irrigated and rainfed plants 14 DAT (Fig. 4A and B). However, noon water potential of rainfed plants was significantly lower (more negative) than in controls 42 DAT. At 66 DAT this difference was also evident in the predawn water potential.

Light response of $\mathrm{P}_{\mathrm{n}}$ was similar in irrigated and rainfed plants 14 DAT (Fig 5A). At 42 DAT the rainfed leaves showed significantly lower $P_{n}$ with respect to irrigated leaves at irradiances $>500$ $\mu \mathrm{mol} \cdot \mathrm{m}^{-2} \cdot \mathrm{s}^{-1}$ (Fig. 5B). Finally, at 66 DAT inhibition of $\mathrm{P}_{\mathrm{n}}$ in rainfed leaves was evident at irradiances $>200 \mu \mathrm{mol} \cdot \mathrm{m}^{-2} \cdot \mathrm{s}^{-1}(\mathrm{Fig}$. $5 \mathrm{C})$. In all cases there were no differences between irrigated and rainfed leaves in the (linear) response of $P_{n}$ at irradiances $<100$ $\mu \mathrm{mol} \cdot \mathrm{m}^{-2} \cdot \mathrm{s}^{-1}$ as also indicated by the $\mathrm{F}_{\mathrm{v}} / \mathrm{F}_{\mathrm{m}}$ measurements.

The nonphotochemical quenching of fluorescence was also similar 14 and 42 DAT in irrigated and rainfed leaves. However, qNP of rainfed leaves was significantly higher than in irrigated leaves 66 DAT.

Daily trends of $P_{n}$ and $g_{s}$ revealed no differences between irrigated and rainfed plants after 14 DAT (Fig. 6A). However, $P_{n}$ and $g_{s}$ of rainfed plants were significantly lower than in the irrigated plants in the central hours of 42 DAT (Fig. 6B) and along the whole 66 DAT (Fig. 6C).

Despite significant inhibition of $\mathrm{P}_{\mathrm{n}}, 42$ and 66 DAT, Rubisco activity and content of rainfed leaves were similar to those of irrigated leaves (Table 1). Stomatal conductance was not different 14 DAT, but was significantly inhibited in rainfed leaves at 42 and 66 DAT (Table 1 and Fig. 3). Transfer conductance of $\mathrm{CO}_{2}$ was not different 14 and 42 DAT, but was significantly inhibited in rainfed leaves 66 DAT (Table 1). Reduction of stomatal and $\mathrm{CO}_{2}$ transfer conductance in rainfed leaves 42 and 66 DAT did not

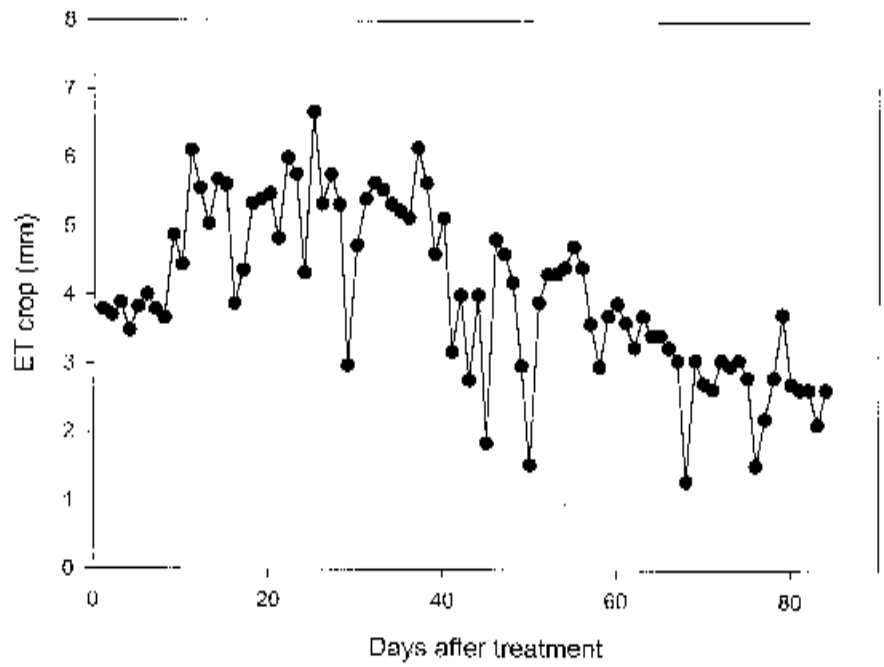

Fig. 2. Calculated evapotranspiration (ETcrop) of the control pepper crop during the experimental period (days after treatment). Calculations were made using the Penman-Monteith formula as described in Materials and Methods. 
result in a reduction of intercellular and chloroplast $\mathrm{CO}_{2}$ concentration. The latter was even significantly higher in rainfed than in irrigated leaves 66 DAT. Reduction of $\mathrm{O}_{2}$ concentration in the air inhibited photorespiration and increased photosynthesis. This stimulation was similar $(\approx 20 \%$ with respect to photosynthesis in ambient air) in rainfed and control plants over the whole experimental period (Table 1).

Leaf area index was reduced by lack of irrigation at $\approx 60 \mathrm{DAT}$ (Fig. 7), i.e., when differences in physiological parameters were observed between rainfed and irrigated plants. A reduction of stem and leaf DW was observed in rainfed plants compared with irrigated plants (Fig. 8). Also in this case, the difference was significant only during the last part of the experiment (from $\approx 60$ DAT). Fruit yield, on the other hand, was higher in rainfed than in irrigated plants for $\approx 60$ DAT. This effect was reversed during the last part of the study and the final yield of fruit was significantly higher in irrigated than in rainfed plants.

\section{Discussion}

The environmental conditions of Mediterranean summers (high evaporative demand and low precipitation) often cause drought stress in plants. Drought stress is almost unavoidable if plants are not acclimated to the Mediterranean conditions and if the water deficit is not supplemented by irrigation. The fast growth of horticultural plants is sustained by generally high

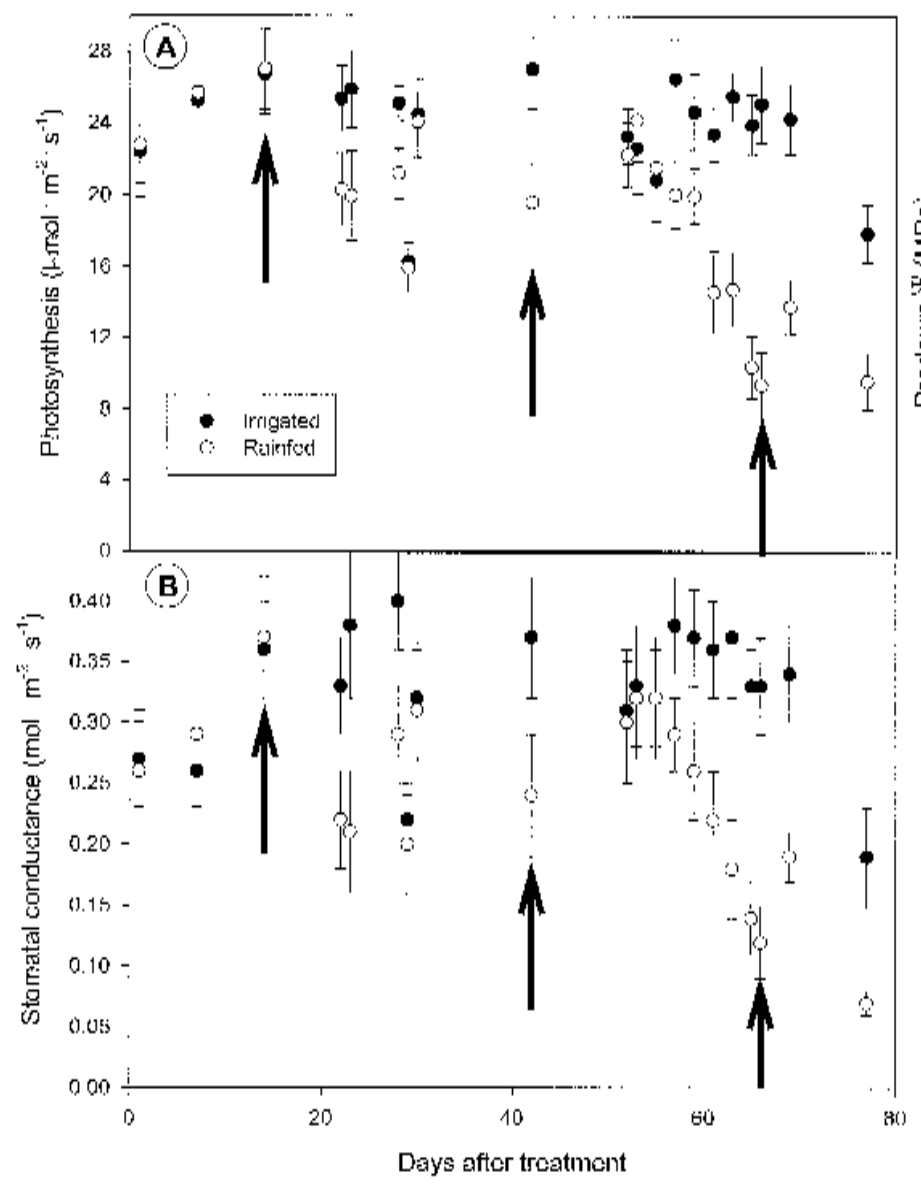

Fig. 3. (A) Photosynthesis and (B) stomatal conductance of irrigated and rainfed leaves measured in the field over the experimental period [days after treatment (DAT)]. Each symbol is based on seven observations and vertical bars represent SE. Arrows indicate photosynthesis and stomatal conductance at 14, 42, and 66 DAT. conductance to gas exchange $\left(\mathrm{CO}_{2}\right.$ and $\left.\mathrm{H}_{2} \mathrm{O}\right)$ and by concomitant high rates of photosynthesis and transpiration. This characteristic, however, also makes horticultural plants particularly vulnerable to drought stress episodes.

In our experiment, scarce precipitation and recurrent drought stress episodes (Figs. 1-2), did not visibly affect the physiological parameters of bell pepper leaves during the first 2 months (Figs. 3-6). Photosynthesis and $g_{s}$ were transiently inhibited in rainfed plants 22 and 42 DAT but both $P_{n}$ and $g_{s}$ were fully restored after 2 heavy rainfalls (Fig. 1). This suggests that the photosynthetic apparatus is resistant to drought stress conditions during the first phase of growth. Even though temporary water shortages caused a reduction of stomatal conductance and photosynthesis, they did not cause permanent damages to the carbon fixation apparatus.

A full set of physiological parameters was monitored during the second transient inhibition of photosynthesis (42 DAT). These measurements showed that only the midday water potential decreased in stressed leaves, while the predawn potential was not affected (Fig. 4). Accordingly, reduction of stomatal conductance in rainfed leaves was limited to the central part of the day (Fig. 6B). It is suggested that at 42 DAT the capacity of water uptake by plants was sufficient to restore the water content when the evapotranspiration demand was reduced (i.e., in the morning and in the evening). This, in turn, restored $\mathrm{P}_{\mathrm{n}}$ similar to that of irrigated plants. Photosynthesis at low irradiance was not inhibited by the stress (Fig. 5B). This may also explain why inhibition

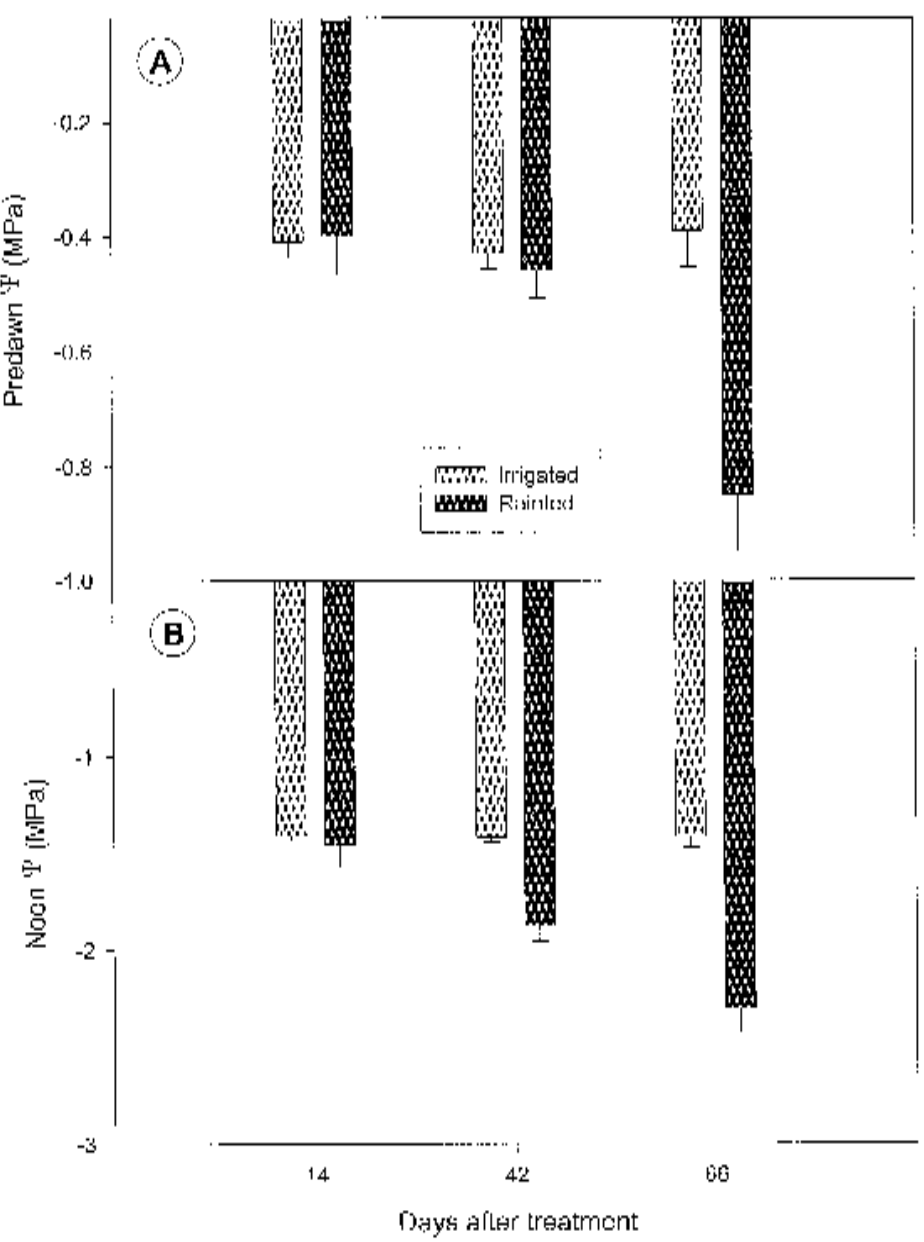

Fig. 4. (A) Predawn and (B) midday water potential (Y) of irrigated and rainfed leaves at 14, 42, and $66 \mathrm{~d}$ after treatment. Each value is based on 16 observations and includes SE. 
was only observed during the central part of the 42 DAT. Response of photosynthesis to low irradiance is an indication of the functionality of the photochemical reactions (Björkman, 1987). Our measurements indicated that the photochemistry of photosynthesis was not impaired by drought stress. This is also confirmed by the fluorescence measurements of the photochemical efficiency of photosystem II $\left(\mathrm{F}_{\mathrm{v}} / \mathrm{F}_{\mathrm{m}}\right)$ illustrated in Fig. 5. However, photosynthesis was significantly reduced at higher irradiance in rainfed leaves. This possibly indicates an impairment of biochemical reactions involved in carbon fixation (Farquhar and Sharkey, 1994) but we did not observe such an impairment in the characteristics of Rubisco 42 DAT (Table 1).

To conclude that the transient reduction of photosynthesis observed during the first phase of growth is only attributable to transient stomatal closure, one should observe a consequent transient reduction of chloroplast $\mathrm{CO}_{2}$ concentration. An addi-

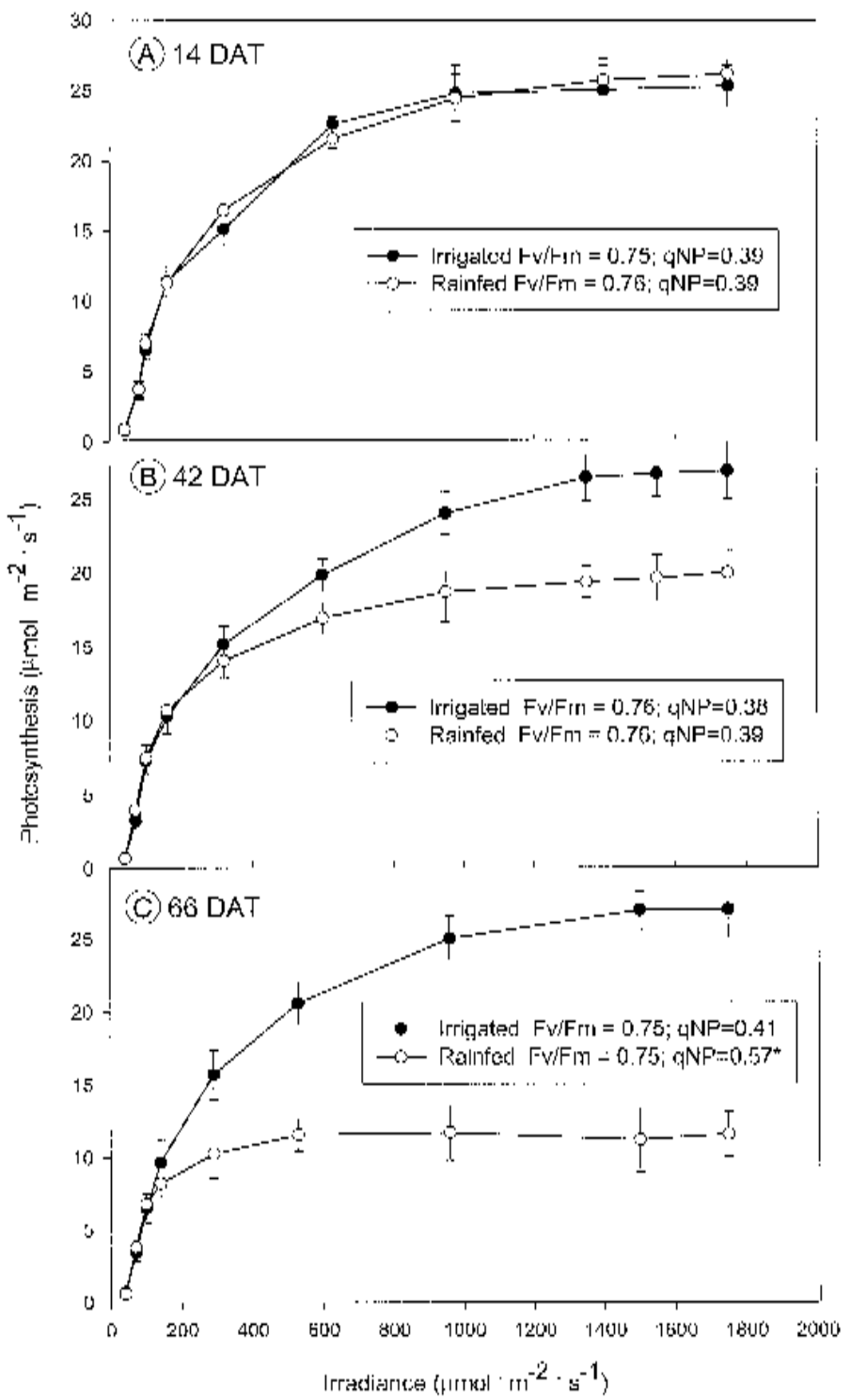

Fig. 5. Photosynthesis response to irradiance, photochemistry efficiency estimated by the variable to maximum fluorescence ratio in the dark $\left(\mathrm{F}_{\mathrm{v}} / \mathrm{F}_{\mathrm{m}}\right)$, and nonphotochemical quenching of fluorescence measured at $800 \mu \mathrm{mol} \cdot \mathrm{m}^{-2} \cdot \mathrm{s}^{-1}$ (qNP) in irrigated and rainfed leaves at (A) 14, (B) 42, and (C) $66 \mathrm{~d}$ after treatment (DAT). Each symbol is based on seven observations and vertical bars $=$ SE. For fluorescence measurements, differences between treatment means on the same DAT were separated by paired $t$ test. * Significantly different at $P<$ 0.05 . tional resistance to $\mathrm{CO}_{2}$ diffusion toward the chloroplasts is generally caused by the mesophyll components (Loreto et al., 1992). This additional resistance may increase under stress conditions (Loreto et al., 1997). However, mesophyll resistance is likely to be controlled by mesophyll structure and particularly by the chloroplast surfaces exposed to gas exchanges (Evans et al., 1994). Therefore, these anatomical features should not undergo rapid changes but rather be the result of ontogenetic or developmental processes. Mesophyll resistance was similar in irrigated and rainfed leaves 42 DAT (Table 1). Thus, it did not contribute to increasing resistance to $\mathrm{CO}_{2}$ diffusion in rainfed leaves. Chloroplast $\mathrm{CO}_{2}$ concentration was not different in rainfed and irrigated leaves 42 DAT (Table 1) thus indicating that resistances to $\mathrm{CO}_{2}$ diffusion did not directly affect photosynthesis.

From 57 DAT until the end of the experiment, $P_{n}$ and $g_{s}$ of rainfed plants were lower than in irrigated plants (Fig. 3) and did not respond positively to two heavy rainfalls occurring during this period (Fig. 1). This indicates that some irreversible impairment of the photosynthetic machinery occurred in rainfed leaves. A

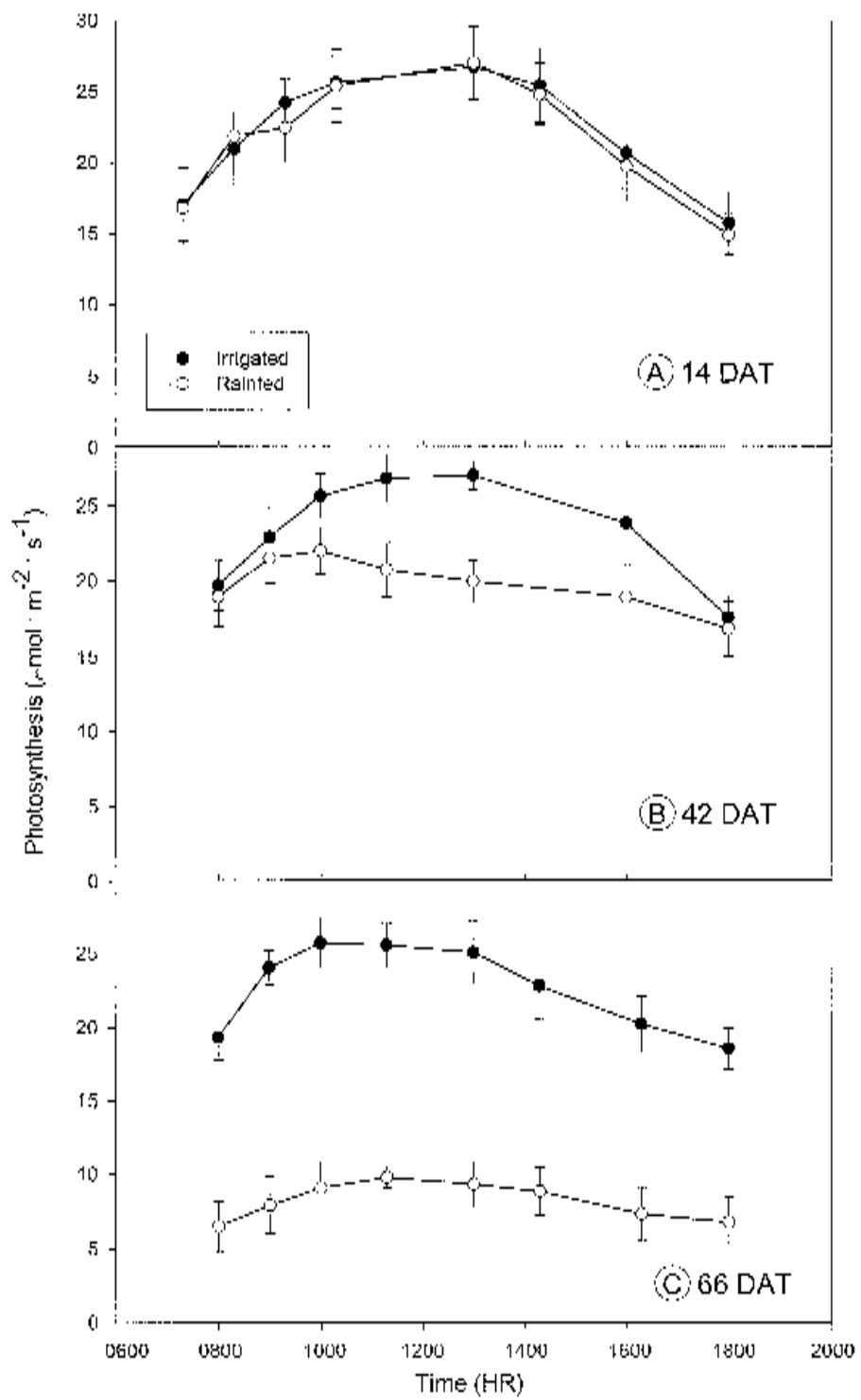

Fig. 6. Diurnal course of photosynthesis in irrigated and rainfed leaves in the field at (A) 14, (B) 42, and (C) $66 \mathrm{~d}$ after treatment (DAT). Each symbol is based on seven observations and vertical bars $=\mathrm{SE}$. 
Table 1. Rubisco activity (Rub A), Rubisco content (Rub C), stomatal conductance $\left(\mathrm{g}_{\mathrm{s}}\right), \mathrm{CO}_{2}$ transfer conductance $\left(\mathrm{g}_{\mathrm{w}}\right)$, intercellular CO $\mathrm{C}_{2}$ concentration $\left(c_{i}\right)$, chloroplast $\mathrm{CO}_{2}$ concentration $\left(c_{c}\right)$, and photosynthetic $\mathrm{O}_{2}$ sensitivity in irrigated and rainfed pepper leaves 14,42 , and $66 \mathrm{~d}$ after treatment (DAT). Values are means $(n=7) \pm$ SE. Differences between treatment means on the same DAT were separated by paired $t$ test.

\begin{tabular}{|c|c|c|c|c|c|c|c|c|}
\hline Treatment & DAT & $\begin{array}{c}\text { Rub A } \\
\left(\mu \mathrm{mol} \cdot \mathrm{m}^{-2} \cdot \mathrm{s}^{-1}\right)\end{array}$ & $\begin{array}{l}\text { Rub C } \\
\left(\mathrm{g} \cdot \mathrm{m}^{-2}\right)\end{array}$ & $\underset{\left(\mathrm{mol} \cdot \mathrm{m}^{-2} \cdot \mathrm{s}^{-1}\right)}{\mathrm{g}_{\mathrm{s}}}$ & $\underset{\left(\mathrm{mol} \cdot \mathrm{m}^{-2} \cdot \mathrm{s}^{-1}\right)}{\mathrm{g}_{\mathrm{w}}}$ & $\begin{array}{c}\mathrm{c}_{\mathrm{i}} \\
\left(\mathrm{mg} \cdot \mathrm{L}^{-1}\right)\end{array}$ & $\begin{array}{c}\mathrm{c}_{\mathrm{c}} \\
\left(\mathrm{mg} \cdot \mathrm{L}^{-1}\right)\end{array}$ & $\begin{array}{c}\mathrm{O}_{2} \\
\text { sensitivity } \\
(\%)\end{array}$ \\
\hline Irrigated & 14 & $113.2 \pm 4.6$ & $4.05 \pm 0.35$ & $0.35 \pm 0.05$ & $0.22 \pm 0.014$ & $271 \pm 11$ & $155 \pm 7$ & $25 \pm 3$ \\
\hline Rainfed & & $115.6 \pm 4.8$ & $4.01 \pm 0.29$ & $0.33 \pm 0.06$ & $0.21 \pm 0.011$ & $267 \pm 10$ & $148 \pm 5$ & $24 \pm 4$ \\
\hline Irrigated & 42 & $111.7 \pm 6.6$ & $3.99 \pm 0.39$ & $0.33 \pm 0.03$ & $0.23 \pm 0.02$ & $267 \pm 13$ & $160 \pm 12$ & $24 \pm 5$ \\
\hline Rainfed & & $111.5 \pm 7.6$ & $4.05 \pm 0.61$ & $0.24^{*} \pm 0.03$ & $0.21 \pm 0.016$ & $264 \pm 14$ & $175 \pm 15$ & $26 \pm 6$ \\
\hline Irrigated & 66 & $105.1 \pm 5.5$ & $3.88 \pm 0.45$ & $0.33 \pm 0.04$ & $0.20 \pm 0.011$ & $267 \pm 11$ & $144 \pm 8$ & $27 \pm 4$ \\
\hline Rainfed & & $104.9 \pm 4.1$ & $3.84 \pm 0.44$ & $0.15^{*} \pm 0.02$ & $0.12^{*} \pm 0.015$ & $276 \pm 15$ & $195^{*} \pm 17$ & $26 \pm 3$ \\
\hline
\end{tabular}

${ }^{*}$ Significantly different at $P<0.05$.

complete set of physiological and biochemical parameters was collected on 66 DAT. At this stage, rainfed plants had a significantly lower water potential than irrigated plants. The difference was not limited to the midday water potential but was also evident for the predawn water potential (Fig. 4). The water potentials of rainfed plants were also lower than those measured 14 and 42 DAT. This may indicate that the capacity of rainfed plant to extract water was diminished at this stage. Consequently, stomatal closure occurred and $\mathrm{P}_{\mathrm{n}}$ was depressed during the entire day in rainfed leaves (Fig. 6C).

Photosynthesis was inhibited at irradiances $>200 \mu \mathrm{mol} \cdot \mathrm{m}^{-2} \cdot \mathrm{s}^{-1}$ and saturated at $600 \mu \mathrm{mol} \cdot \mathrm{m}^{-2} \cdot \mathrm{s}^{-1}(\approx 1 / 3$ of the maximum solar irradiance) in rainfed leaves but the linear response of photosynthesis to light (i.e., the response at irradiances $<100$ $\mu \mathrm{mol} \cdot \mathrm{m}^{-2} \cdot \mathrm{s}^{-1}$ ) was still comparable to that of irrigated leaves (Fig. 5C). The yield of dark fluorescence was also unchanged. Therefore, there was no evidence of photochemical injury in rainfed leaves at 66 DAT. Only a significant increase of qNP, indicating a high amount of dissipated energy was observed in rainfed leaves (Fig. 5C).

We examined if Rubisco characteristics could be responsible for reduced photosynthesis at moderate and high irradiances but, as at 42 DAT, Rubisco activity and content were still high and comparable in rainfed and irrigated leaves at 66 DAT (Table 1). Since no evidence of photochemical and biochemical impairment was found in rainfed leaves, we examined if photosynthesis reduction at 66 DAT was caused by restrictions to $\mathrm{CO}_{2}$ diffusion.

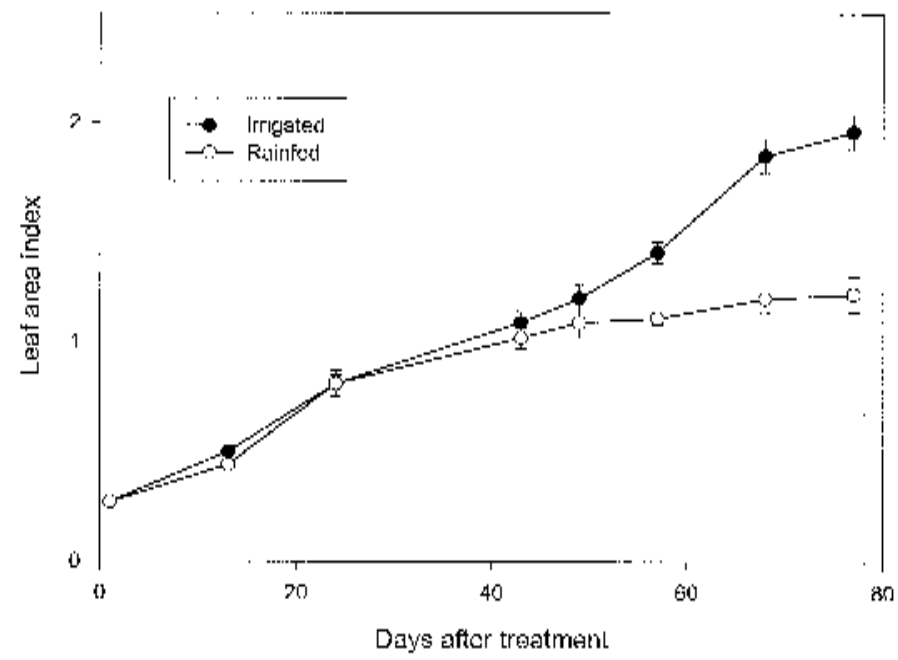

Fig. 7. Leaf area index of irrigated and rainfed plants during the experimental period. Each symbol is based on seven observations and vertical bars $=\mathrm{SE}$.
Stomatal conductance was significantly lower in rainfed than in irrigated leaves. Moreover, contrary to what was found at 42 DAT, we observed that, at 66 DAT, the $\mathrm{CO}_{2}$ transfer conductance of rainfed leaves was significantly lower than that of irrigated leaves. Thus, mesophyll resistance contributed to the total resistance to $\mathrm{CO}_{2}$ diffusion at $66 \mathrm{DAT}$. The reduction of $\mathrm{CO}_{2}$ transfer

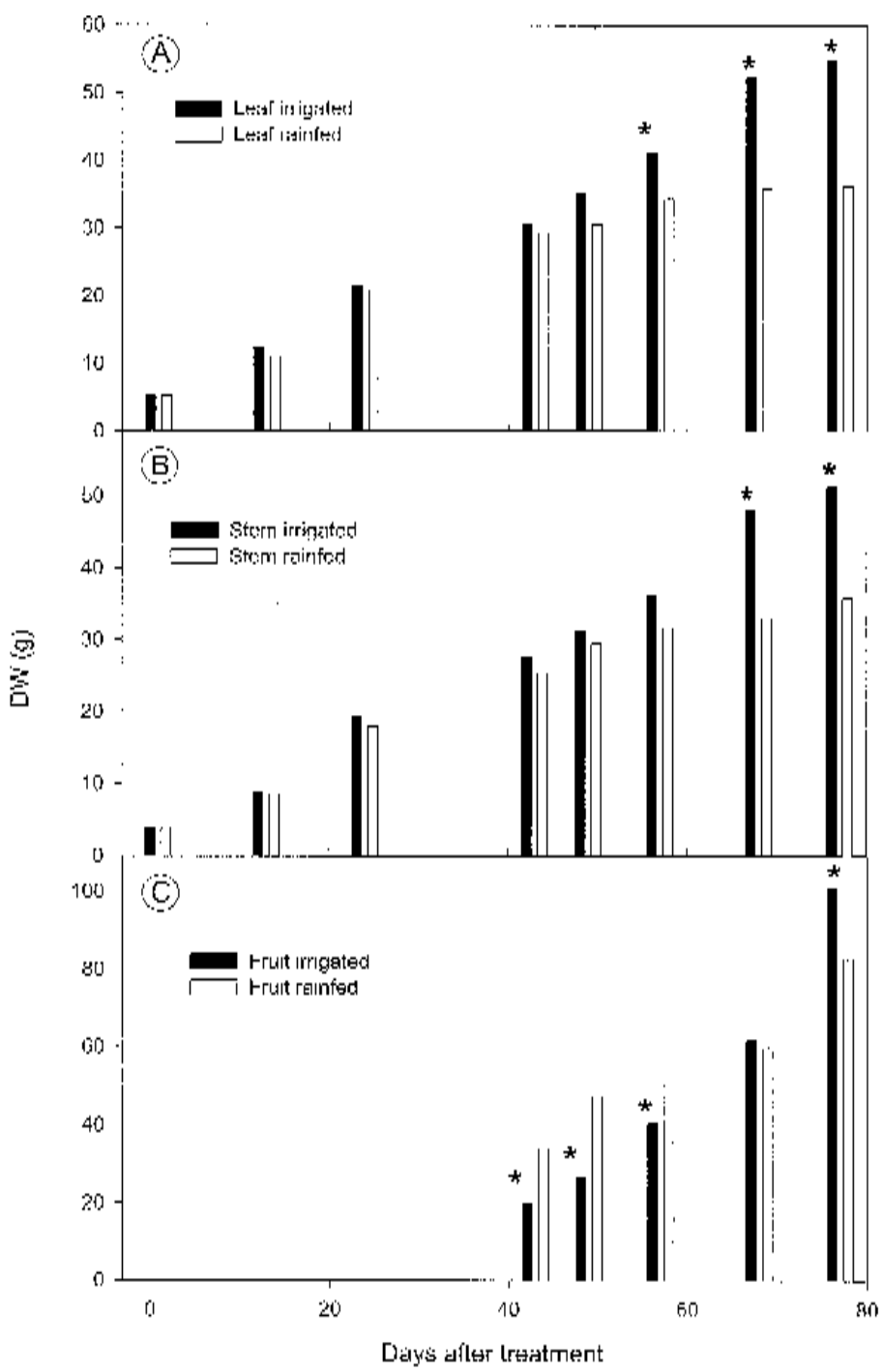

Fig. 8. Aboveground DW accumulation in irrigated and rainfed plants partitioned among (A) leaves, (B) stems, and (C) fruit, during the experimental period. Within the same day after treatment, means were separated by paired $t$ test. "Significantly different at $P<0.05$. 
conductance is presumably associated to changes of mesophyll structure and is therefore not fully reversible as also demonstrated for salt stress by Delfine et al. $(1998,1999)$. Despite the further increase of diffusion resistances, the chloroplast $\mathrm{CO}_{2}$ concentration in rainfed leaves was even higher than in irrigated leaves (Table 1). Thus, photosynthesis was inhibited by factors other than substrate $\left(\mathrm{CO}_{2}\right.$ concentration $)$ availability. Patchy stomatal closure may occur in drought stressed leaves (Downton et al., 1988; Sharkey and Seemann, 1989). This would overestimate the intercellular and chloroplast $\mathrm{CO}_{2}$ concentrations (Terashima, 1992). To verify if this was the reason why we observed a high chloroplast $\mathrm{CO}_{2}$ concentration in rainfed leaves, we measured sensitivity of photosynthesis to low $\mathrm{O}_{2}$ exposure. Under these nonphotorespiratory conditions photosynthesis is normally stimulated by $\approx 20 \%$ to $30 \%$. A higher stimulation likely indicates the occurrence of stomatal patchiness (Bongi and Loreto, 1989; Terashima, 1992). We found similar $\mathrm{O}_{2}$ sensitivity in rainfed and irrigated leaves all over the experimental period (Table 1). Therefore, the occurrence of stomatal patchiness should not have caused an overestimation of the chloroplast $\mathrm{CO}_{2}$ concentration.

It has been found that ATP content often decreases in drought stressed leaves (Kaiser, 1987). This reduction has been attributed to the loss of ATP synthase coupling factor 1 which, in turn, builds up the transthylakoidal $\Delta \mathrm{pH}$ (Tezara et al., 1999). It has also been observed that $\Delta \mathrm{pH}$ is associated with nonphotochemical quenching of fluorescence (Krause and Weis, 1991). Therefore, the observed increase of qNP in rainfed leaves 66 DAT may indicate the occurrence of reduced ATP synthesis which limits carbon metabolism. It is noteworthy that qNP values of irrigated and rainfed leaves were consistent with those reported by Tezara et al. (1999) for plants with progressively increasing water potentials. If our hypothesis is correct, then ATP synthesis may limit photosynthesis not only when drought stress is rapidly achieved but also when the stress slowly develops as in field conditions.

In rainfed and irrigated plants, leaf area index and DW of leaves and stems were similar until $\approx 50$ to 60 DAT, then started to become significantly lower in rainfed plants than in irrigated plants. When photosynthesis and growth parameters are compared in rainfed and irrigated plants, it appears that carbon fixation effectively controlled plant growth and vegetative biomass. Passioura (1994) noted that drought stress often affects growth characteristics earlier than photosynthesis and suggested that photosynthesis may eventually be limited by end-product accumulation. However, drought stress episodes which transiently impair $\mathrm{P}_{\mathrm{n}}$ (20 to $\left.50 \mathrm{DAT}\right)$ did not affect plant growth. Late in the season, when drought stress was not relieved, plant growth was also affected. At this stage heavy rainfalls occurred and the ETcrop was even lower than early in the season. Plants should not have suffered drought stress under these conditions. There is a close association between biomass accumulation and transpiration in plant stands (Sinclair, 1994). It is possible that the physiological changes occurring in aging plants (mainly reduced stomatal conductance) are responsible for the reduced capacity of water uptake from the soil and for subsequent reduction of growth. This, in turn, may cause accumulation of photosynthetic products per area unit, which eventually inhibits photosynthesis (Sharkey, 1990).

Interestingly, DW of fruit was stimulated in rainfed plants during the first part of the experiment and irrigated plants produced fruit DWs higher than rainfed plants only after 60 DAT. Thus, moderate drought stress episodes, provided plants are able to recover from them, may influence the strength of carbon sinks, redirecting carbon toward the reproductive organs. Subsequent early fruiting may even be a desirable commercial characteristic.

In conclusion, our research indicates that under field conditions, typical of summers in the Mediterranean, the photosynthetic apparatus of bell pepper plants is resistant to drought stress episodes at least during the first phase of growth when photosynthesis inhibition is overcome. In older plants, photosynthesis limitations become permanent. These limitations are not caused by the observed increase of resistances to $\mathrm{CO}_{2}$ diffusion in drought stress conditions, but perhaps by reduced ATP synthesis. Photosynthesis limitations may reduce plant growth but may not necessarily decrease fruit yield if the stress is transient. This finding may have important implications for agricultural practices aimed at saving water in arid and semiarid growing regions.

\section{Literature Cited}

Alvino A., M. Centritto, and F. De Lorenzi. 1994. Photosynthesis response of sunlit and shade pepper (Capsicum annuum) leaves at different positions in the canopy under two water regimes. Austral. J. Plant Physiol. 21:377-391.

Alvino A., S. Delfine, and M. Mori. 1999. Foliar senescence in maize plants grown under different water regimes. Agronomie 19:591-601.

Björkman O. 1987. High-irradiance stress in higher plants and interaction with other stress factors, p. 13-18. In: J. Biggens (ed). Progress in photosynthesis research. vol. IV. Nijhoff, Dordrecht, The Netherlands. Bongi G. and F. Loreto. 1989. Gas-exchange properties of salt-stressed olive (Olea europea L.) leaves. Plant Physiol. 90:1408-1416.

Brooks A. and G.D. Farquhar. 1985. Effect of temperature on the $\mathrm{CO}_{2} /$ $\mathrm{O}_{2}$ specificity of ribulose-1,5-bisphosphate carboxylase/oxygenase and the rate of respiration in light. Planta 165:397-406.

Cornic G. and A. Massacci. 1996. Leaf photosynthesis under drought stress, p. 347-366. In: N. Baker (ed.). Photosynthesis and the environment. Kluwer, Dordrecht, The Netherlands.

Delfine S., A. Alvino, M.C. Villani, and F. Loreto. 1999. Restriction to carbon dioxide conductance and photosynthesis in spinach leaves recovering from salt stress. Plant Physiol. 119:1101-1106.

Delfine S., A. Alvino, M. Zacchini, and F. Loreto. 1998. Resistances to $\mathrm{CO}_{2}$ diffusion in salt stressed leaves. Austral. J. Plant Physiol. 25:395402.

Doorenbos J. and A.H. Kassam. 1986. Yield response to water. Food and Agricultural Organization (FAO) Irr. Drainage paper 33.

Downton W.J.S., B.R. Loveys and W.J.R. Grant. 1988. Non-uniform stomatal closure induced by water stress causes putative non-stomatal inhibition of photosynthesis. New Phytol. 110:503-509.

Evans J.R., S. von Caemmerer, B.A. Setchell, and G.S Hudson. 1994. The relationship between $\mathrm{CO}_{2}$ transfer conductance and leaf anatomy in transgenic tobacco with a reduced content of Rubisco. Austral. J. Plant Physiol. 21:475-495.

Farquhar G.D. and T.D. Sharkey. 1994. Photosynthesis and carbon assimilation, p. 187-210. In: K.J. Boote, J.M. Bennett, T.R. Sinclair, and G.M. Paulsen (eds.). Physiology and determination of crop yield. Amer. Soc. Agron., Wis.

Faver K.L., T.J. Gerik, P.M. Thaxton, and K.M. El-Zik. 1996. Late season water stress in cotton: II. Leaf gas exchange and assimilation capacity. Crop Sci. 36:922-928.

Genty B., J-M. Briantais, and N.R. Baker. 1989. The relationship between the quantum yield of photosynthetic electron transport and quenching of chlorophyll fluorescence. Biochem. Biophys. Acta, 990:87-92.

Gimenez C., V.J. Mitchell, and D.W. Lawlor. 1992. Regulation of photosynthetic rate of two sunflower hybrids under water stress. Plant Physiol. 98:516-524.

Hanson A.D. and W.D. Hitz. 1982. Metabolic responses of mesophytes to plant water deficits. Annu. Rev. Plant Physiol. 33:163-203.

Harley P.C., F. Loreto, G. Di Marco, and T.D. Sharkey. 1992. Theoretical considerations when estimating the mesophyll conductance to $\mathrm{CO}_{2}$ 
flux by analysis of the response of photosynthesis to $\mathrm{CO}_{2}$. Plant Physiol. 98:1429-1436.

Kaiser W.M. 1987. Effect of water deficit on photosynthetic capacity. Physiol. Plant. 71:142-149.

Krause G.H. and E. Weis. 1991. Chlorophyll fluorescence and photosynthesis: The basics. Annu. Rev. Plant Physiol. Plant Mol. Biol. 42:313349.

Loreto F., S. Delfine, and A. Alvino. 1997. On the contribution of mesophyll resistance to $\mathrm{CO}_{2}$ diffusion to photosynthesis limitation during water and salt stress. Acta Hort. 449:417-422.

Loreto F., G. Di Marco, D. Tricoli, and T.D. Sharkey. 1994. Measurements of mesophyll conductance, photosynthetic electron transport and alternative electron sink of field grown wheat leaves. Photosyn. Res. 41:397-403.

Loreto F., P.C. Harley, G. Di Marco, and T.D. Sharkey. 1992. Estimation of mesophyll conductance to $\mathrm{CO}_{2}$ flux by three different methods. Plant Physiol. 98:1437-1443.

Lurie S., B. Shapiro, and S. Ben-Yehoshua. 1986. Effects of water stress and degree of ripeness on rate of senescence of harvested bell pepper fruit. J. Amer. Soc. Hort. Sci. 111:880-885.

Mojayad F. and C. Planchon. 1994. Stomatal and photosynthetic adjustment to water deficit as the expression of heterosis in sunflower. Crop Sci. 34:103-107.

Ortiz-Lopez A., D.R. Ort, and J.S. Boyer. 1991. Photophosphorylation in attached leaves of Helianthus annuus at low water potentials. Plant Physiol. 96:1018-1025.

Passioura J.B. 1994. The yield of crops in relation to drought, p. 343-359. In: K.J. Boote, J.M. Bennett, T.R. Sinclair, and G.M. Paulsen (eds.). Physiology and determination of crop yield. Amer. Soc. Agron. Madison, Wis.

Quick W.P., M.M. Chaves, R. Wendler, M. David, M.L. Rodrigues, J.A.
Passharino, J.S. Pereira, M.D. Adcock, R.C. Leegood, and M. Stitt. 1992. The effect of water stress on photosynthetic carbon metabolism in four species grown under field conditions. Plant Cell Environ. $15: 25-35$.

Sharkey T.D. 1990. Feedback limitation of photosynthesis and the physiological role of ribulose bisphosphate carboxylase carbamylation. Bot. Mag. 2:87-105.

Sharkey T.D., L.V. Savitch, and N.D. Butz. 1991. Photometric method for routine determination of k-cat and carbamylation of Rubisco. Photosyn. Res. 28:41-48.

Sharkey T.D. and J.R. Seemann. 1989. Mild water stress effects on carbon-reduction-cycle intermediates, ribulose bisphosphate carboxylase activity, and spatial homogeneity of photosynthesis in intact leaves. Plant Physiol. 89:1060-1065.

Sinclair T.R. 1994. Limits to crop yield?, p. 509-532. In: K.J. Boote, J.M. Bennett, T.R. Sinclair, and G.M. Paulsen (eds.). Physiology and determination of crop yield. Amer. Soc. Agron. Madison, Wis.

Terashima I. 1992. Anatomy of non-uniform leaf photosynthesis. Photosyn. Res. 31:195-212.

Tezara W., V.J. Mitchell, S.D. Driscoll, and D.W. Lawlor. 1999. Water stress inhibits plant photosynthesis by decreasing coupling factor and ATP. Nature 401:914-917.

van Kooten O. and J.F.H. Snell. 1990. The use of chlorophyll fluorescence nomenclature in plant stress physiology. Photosyn. Res. 25:147150.

von Caemmerer S. and G.D. Farquhar. 1981. Some relationships between the biochemistry of photosynthesis and the gas exchange of leaves. Planta 153:376-387.

Yanez C.E., A. Alvino, V. Magliulo, and P. Steduto. 1992. Pepper response to mild conditions of combined soil-water and salinity stress. Adv. Hort. Sci. 6:3-10. 